\title{
How Can Modifications of Meaning Influence Argumentation? The Concept and Typology of Semantic Arguments
}

\author{
Jakub Pruś ${ }^{1}$ (D) \\ Accepted: 13 October 2020 / Published online: 23 October 2020 \\ (c) The Author(s) 2020
}

\begin{abstract}
The aim of this article is to show how modifications of meaning can influence argumentation. I present the basic concept of so-called 'semantic argumentation,' its definition, and its different variants. I analyse the various kinds of argument in which meanings of terms are modified in support of a persuasive goal. The analysis of different semantic arguments reveals certain structures and patterns that are needed to construct a typology of such arguments. I thus outline a basic concept of argumentation based on modifications of meaning, before presenting various examples of such arguments together with an analysis of their structures, and then, finally, constructing a typology for them.
\end{abstract}

Keywords Argument from verbal classification - Argument from definition · Semantic argument $\cdot$ No true Scotsman fallacy $\cdot$ Persuasive definition

\section{Introduction}

The notion of semantic arguments continues to receive only a limited degree of acknowledgement in argumentation theory. Some scholars seek to analyse only the influence of emotional language upon argumentation, yet there has been scant research into the role of definition, redefinition and classification in this areawhether it be manifested in political debates or advertisements, or in academic or legal discourse. However, the concept of semantic arguments is much broader than manipulating emotions by using the right words in the discussion. The arguments modifying the meaning to support the persuasion goal are very common and powerful. This work analyses various examples of such arguments, taken from legal, political and ethical discourses, and shows that semantic arguments have different

Jakub Pruś

jakub.prus@ignatianum.edu.pl

1 Philosophy Department, Jesuit University Ignatianum in Krakow, Cracow, Poland 
types, which can be distinguished and carefully described. The present paper is an attempt to introduce the concept of semantic arguments in a more or less systematic fashion, and to construct a typology of such arguments. The latter task is arguably crucial to further investigative work on semantic arguments, such as evaluating the logical and/or ethical significance of such arguments. Therefore, this research is another step in systematizing the concept of semantic argument, which is necessary for providing criteria of correctness of such arguments. The significance of this task is great, for-as it will be showed-semantic argument is a common and powerful type of argument, which could also be used in a rational discourse. Therefore, it is also a need of society to know how such arguments are built and how to evaluate them. Thus, it is our task to describe the various types of semantic arguments and to provide some critical tools for dealing with semantic arguments. This paper aims to construct a typology of such arguments, to which in future we will be able to formulate critical questions.

\section{Semantic Argumentation: The Basic Concept and its Definition}

The notion of 'semantic argument' was used for the first time by Teresa Hołówka-a Polish logician who, in her studies of logic, has sought to continue the intellectual tradition of the Lvov-Warsaw school. In her book Kultura logiczna w przykładach [Logical Culture in Examples], she presents the notion of semantic arguments, in the sense of arguments that aim to support certain classifications either by referring to the accepted meaning of a term or introducing a new one for it (Hołówka 2012 , p. 116). Although she does not provide a clear definition of these arguments, her intuitions seem promising inasmuch as they point towards the possibility of outlining a new model of argumentation in which interlocutors argue about classification and modify the meanings of the terms they are using - as when, say, one redefines 'betrayal' in order to be in a position to classify something as 'traitorous'. Thus, it seems to reasonable to think that Hołówka's intuitions regarding the nature of semantic arguments ought to be further developed to provide such a model of argumentation, which in turn may prove useful when analysing legal, scientific or political debates. ${ }^{1}$ Here, then, is a more precise definition of semantic argumentation itself:

Semantic argumentation is a form of argumentation in which a proponent modifies the meaning of a term, or introduces a new meaning, in order to support his or her persuasive goal (Pruś 2019).

\footnotetext{
${ }^{1}$ The question of the role of semantics in the argumentation is also developed, in a different paradigm than presented here, that is in the pragma-dialectical doctrince of strategic maneuvering (Eemeren 2010). Modifying the meaning in the discussion seems to be one of the species of the strategic maneuveringsee analysis of such strategies with use of persuasive definitions (Zarefsky 2006) or dissociation (Feng et al. 2020).
} 
In arguments of this type, there is at least one premise containing a redefinition or classification that serves to modify the meaning of a term employed there. Any premise that includes within itself a persuasive definition will be an instance of a definitional premise in this sense. Let us consider the following example: 'tolerance is about respecting people whose opinions I agree with, and I don't agree with conservatism, therefore I do not have to respect conservatives to count as tolerant'. In the above instance, the definitional premise is clearly a move that aims to introduce a certain understanding of tolerance. Given that premise, one can straightforwardly proceed to construct an argument that will be valid, so the burden of the argumentation, so to speak, rests with the definitional premise itself and, more specifically, with the way in which it seeks to manipulate the meaning of the relevant term.

Chaïm Perelman, Polish-Belgian philosopher, has also analysed the role of definition in the argumentation-his results have a great significance for the concept of semantic arguments. In his most famous work The New Rhetoric Perelman, together with Lucie Olbrechts-Tyteca, he pointed out several ways, in which modification of meaning through definition can be used to support the argumentation (or, as he says, quasi-logical argumentation). Above all, he sees that definitions "are always matter of choice" (1969, p. 448) and that they are never neutral, and pretending that the definition that one is providing in discussion is neutral may be powerful way of persuasion (1969, pp. 153-154). He also distinguishes definitions called 'condensed', which "point out the essential elements of a descriptive definition" (1969, p. 211). Perelman's analysis of this type of definition sheds some light on application so called 'essential' definition in the argumentation. He also points out various way in which definition may be justified in the discussion (e.g. etymology, consequences) and analyses-as did Charles Stevenson before him-the role of emotional terms used in the definition. The last crucial insight for the concept semantic arguments is the idea of dissociative definitions, which introduce new, 'correct' or 'precise' meaning and displace the previous meaning with a new one (1969, pp. 444-450). This idea of the definition that dissociate meaning will be very useful in the further analysis.

Even so, not every semantic argument need include an explicit definitional (or redefinitional) premise. There are also arguments that involve a classificatory premise: i.e. one that assigns some property to something just because it belongs to some category-e.g. 'every lie is a trespass against people and God'. On the basis of such a premise, one can conclude that if something has a certain property ('is a lie'), then it also has another property ('is a trespass'). This is known as 'argument from verbal classification' (Walton et al. 2008, p. 319).

It is worth noting that modifications of meaning can involve changing not only the denotations of terms (as in 'death is simply brain death, and not also a cessation of breathing'), but also their connotations (as in 'betrayal is an ability to make a rational decision in spite of irrational or unfavourable commitments'). These represent two distinct types of manipulation of meaning. The former adjusts the definition so that it now includes (or excludes) something, thus altering the denotation so as to lend support to some other persuasive goal (as in, say, 'my husband's brain is already dead, therefore I can now inherit the family fortune'). The latter, meanwhile, does not change the denotative meaning at all, but only seeks to influence the 
connotations of a term by redefining it-for example, by shifting a negative connotation ('betrayal') in the direction of something more positive ('rationality' as a positive value), so that it is no longer as shameful to be a traitor as before. In this way, one can change the connotations of a term to lend support to a persuasive goal (e.g. a politician, who is well known to be fickle, might deploy a redefinition of 'betrayal' to change people's emotional attitude towards him or her). Thus, a semantic argument modifies some meaning or other, either through persuasive definition or verbal classification, and this will involve influencing our understanding of either denotative or connotative forms of meaning. Before moving on to the analysis of different types of such argumentation, it is worth briefly introducing the concept of 'persuasive definition' (hereafter 'PD') itself.

\section{Persuasive Definition and Semantic Arguments}

The idea of a PD was first introduced by Stevenson in his article Persuasive Definitions (1938), and subsequently further developed in his book Ethics and Language (1944). He defines two notions there: persuasive definition and quasi-persuasive definition. The former involves changing the denotation (descriptive meaning) of an emotionally-laden word in order to predicate it of some new class of objects, while the latter only involves changing the connotation (emotive meaning) of the term, leaving its denotation unchanged (Stevenson 1944; pp. 280-281, 1938, pp. 333-334). For instance, one can define 'courage' as 'strength in the face of adverse public opinion', and then go on to call a controversial decision 'courageous'. But one could equally quasi-define 'adultery' as 'applying the principles of democracy to love' in order to give 'adultery' a positive value in place of its existing negative connotations. These two tactics are nowadays together referred to as persuasive definitions (Macagno and Walton 2008b, p. 204).

Although there have been many studies of PDs in contemporary logic, none of these mentions the great work of the Polish philosopher Tadeusz Pawłowski, ${ }^{2}$ who further developed Stevenson's conception of what persuasive definitions amount to, and created an expanded typology for them. As we shall see, his achievements will turn out to be of considerable use to our own analysis, especially when it comes to creating a typology of semantic arguments.

Pawłowski divided PDs into three types: (i) PDs aimed to change the extension of definiendum, (ii) PDs aimed to change emotional value of definiendum, (iii) PDs aimed at exchanging a given term for another with a different emotional value. PDs of the first kind are those definitions that modify a term's extension to include or exclude some object, as when one redefines 'tolerance' to classify some intolerant individual as 'tolerant'. It also includes PDs which add evaluative term

\footnotetext{
2 Tadeusz Pawłowski (1924-1996), a student of Tadeusz and Janina Kotarbiński, was a third-generation member of the Lvov-Warsaw School. In his works, he sought to further develop the intellectual legacy of the school, paying great attention to clarity of thought, seeking to render philosophical terms more precise, and pursuing the so-called 'logical culture' distinctive of that movement more generally.
} 
to definiendum in order to adjust its extension to one's needs. ('true courage', 'real man', 'just law'). PDs of the second sort are definitions, which change emotional value of the term, as in the Pawłowski's example: "Everything the artist spits out is art" (1978, p. 235). PDs of the third category are not strictly definitions, as they do not in reality define some term, but instead exchange it for another (possessing connotations that will lend support to one's persuasive goals). Pawłowski called this last group 'definitions aimed at exchanging a given term for another with a different emotional value' (1978, p. 237). Later, this name was shortened to 'synonymous definitions'. I will not myself analyse the concept of PDs any further here, as many studies of this topic already exist (Walton 2001, 2005; Macagno and Walton 2008a, 2014; Walton and Krabbe 1995). Instead, I shall focus on employing Pawłowski’s typology as presented above in order to create a typology for semantic arguments themselves, where these include PDs.

Stevenson's 'suspicious' approach towards PDs, and his construal of them as instances of fallacious thinking, remains a commonly held stance amongst logicians and philosophers even today. In response, let us recall the work of Douglas Walton, who 'defends' PDs against the charge of being deceptive or fallacious. Analysing some cases of PDs, Walton shows that they are not necessarily fallacious, and that they can indeed be used (and are so) in rational debate (Walton 2001, pp. 128-9). $\mathrm{He}$ analyses the case of a redefinition of 'culture' that would enable a rude person to be classified as cultured: there is nothing deceptive here, one is just proposing a broader understanding of what it means to be 'cultured', and it is obvious why one is doing that. Similarly, the other case studies show that PDs are not always deceptive: behind these redefinitions there are theories that purport to support them (see for example redefinition of rape, which involves a particular, e.g. feminist or conservative, anthropology ${ }^{3}$ ), and these can themselves be challenged and discussed, so they should not be treated as fallacious, but rather simply as arguments. Of course there is more to this topic, especially regarding the problem of nominalism versus essentialism as it relates to definitional matters ${ }^{4}$ (Walton 2005, pp. 173-184). I will further call definition persuasive if its acceptance offers a solution in the discussion and there is alternative definition of a given term.

Therefore, the concept of semantic argument-to put it simple-includes all arguments based on the modification of meaning: thus it includes arguments from definition and to definition, arguments using persuasive definitions (following Stevenson's characteristics and Pawłowski’s typology), quasi-persuasive definitions,

\footnotetext{
3 As Aberdein puts it: "debate between radical feminists and other parties, most notably liberal feminists, over the definition of rape. The liberal definition is that rape is sexual intercourse in which one party does not offer informed, rational consent. The radical feminists contend that rape can only be understood as serving to reinforce a patriarchal hegemony. Hence they can define rape as existing any time sexual intercourse occurs when it has not been initiated by the woman out of her own genuine affect and desire and be prepared to embrace the consequence that under this definition, most of the decently married bedrooms across America are the settings for nightly rape" (Aberdein 2000).

${ }^{4}$ Defining is understood hereinafter as a speech act, in which one distinguishes certain object or class of objects by setting its extension clearly. This pragmatic account of definition is very different from essentialist one, but — as it will be showed-it is more beneficial for argumentation theory.
} 
and classification arguments: from verbal classification and from definition to verbal classification. ${ }^{5}$ One might ask critically, what is the purpose of introducing a new concept of argument which consists of various types of already accepted arguments? The response to this is following: all these types of arguments share the same core: they are based on the modification of meaning (denotation of connotation). Moreover, the intuition to build a model of argument, which will include various types of arguments based on modification of meaning was shared by various logicians and philosophers, like Pawłowski, Perelman, Hołówka (e.g. compare Pawłowski’s concept of 'persuasive argument', which includes arguments based on various types of PDs). It may also bring a new perspective in the argumentation theory, that is to say, focus more researchers on the role of semantics in argumentation.

Having said this, we are now in a position to survey the different types of PD and verbal classification. I shall present various arguments that are based on these, in the hope that the analysis of each of them in turn will reveal points of interest. Then I shall subsequently use these results to construct a typology for semantic arguments.

\section{Examples of Semantic Arguments}

Pawłowski’s typology has a great impact on the analysis of the semantic arguments, however it requires some modification: two first types overlap with each other-it is possible that definition not only changes the extension of definiendum, but also changes its emotional value (connotation). What's more, criterion of emotional value of definition might be hard to apply, for this property depends on the subject and the context, in which definition is formulated. The second type might be reformulated to the definitions changing emotional value of definiendum without changing its extension-which makes it Stevenson's quasi-persuasive definition (quasi-PD). The third type of Pawłowski's typology of PDs was later shortened to synonymous persuasive definitions. Therefore, typology of PDs should be changed as follows: PDs changing the extension of definiendum, quasi-PDs, synonymous PDs. It can be further developed, but it exceeds the aim of this article. The typology of semantic arguments involving PDs will be built accordingly to the modified typology of PDs. Afterwards I shall present the other two kinds: namely, arguments from verbal classification and arguments from definition to verbal classification. These, together, will constitute the basic types of semantic argument.

\footnotetext{
5 The distinction between arguments for a definition and arguments using a definition (classifying from definition) comes from Perelman: "The argumentative character of definitions always presents two closely connected aspects which must nevertheless be distinguished, since they deal with two phases of the reasoning: definitions can be supported or validated by argument; they themselves are arguments" (1969, p. 213). I refer to the latter, following Walton, Reed and Macagno, as 'arguments from definition to verbal classification'. To avoid confusion, the former will be simply named "arguments using PD". It is worth to note that the first traits of these two types of arguments can be found in Peter of Spain's writings, where he discuss 'locus from definition' and the relationship of definitio-definitum and definitumdefinitio (Rigotti and Greco 2019, p. 107).
} 


\subsection{Arguments Including Persuasive Definition Changing the Extension of Definiendum}

Case 1 Let's finally say what the term 'racism' means. It is simply treating people unequally on the basis of their ethnicity. Thus the Democratic Union is a racist party. They seek to introduce an electoral law privileging ethnic minorities (Hołówka 2012, p. 117).

The above example uses type (ii) from Pawłowski's typology of PDs. It introduces a new definition into a premise, where this changes the extension of the definition in order to include or exclude something. In this example, an overly broad definition of racism is provided that then makes it possible to call a certain party 'racist'. The burden of the whole argument lies on this premise. The example may seem trivial, as one can simply cast doubt upon this definition or present an alternative one. However, it is not always clear that somebody is providing a definition that changes some meaning and, what is more, providing a precise definition is itself sometimes problematic. Anyway, the term 'racism' carries highly negative connotations in the political sphere, and almost no party or politician would wish to be branded a 'racist'. The argumentation scheme looks as follows:

Definition Premise: Racism is about treating people unequally on the basis of their ethnicity.

Individual Premise: Democratic Union seeks to introduce an electoral law privileging ethnic minorities-which is treating people unequally.

Conclusion: Democratic Union is a racist party.

Let us now turn to the following example, in which such emotionally charged and impactful terms are less important:

Case 2 Bribery is about giving somebody something of significant value to make him do something we want. My client just wanted to avoid being called from one police office to another, so he gave the policeman five euros. Let's be serious-you cannot classify this as 'bribery', can you? (Hołówka 2012, p. 118).

This type of argument is a case of the definition changing the extension of the definiendum. It was already known to Aristotle, named later by the scholastics called it a dicto simpliciter ad dictum secundum quid, which means 'from the unqualified statement to the qualified one' (Parry and Hacker 1991, p. 438). The secundum quid tactic often pretends to be just rendering the meaning of a term more precise, whereas in fact it changes its meaning to support a persuasive goal. In this instance, a definition of bribery is 'made more precise' through the proponent's appeal to the notion of 'something of significant value', and by suggesting that five euros is not so valuable. With the terms thus redefined, giving five euros to a policeman can be excluded from the extension of the word 'bribery'. This makes it clear that persuasive definitions, and so semantic arguments also, are not only about using 
emotionally charged and impactful terms. Now let us discuss another subtype of such argument, which also modifies the extension of definiendum, but in a different manner:

Case 3 Imagine some Scottish chauvinist settled down one Sunday morning with his customary copy of The News of the World. He reads the story under the headline, 'Sidcup Sex Maniac Strikes Again'. Our reader is, as he confidently expected, agreeably shocked: 'No Scot would do such a thing!' Yet the very next Sunday he finds in that same favourite source a report of the even more scandalous on-goings of Mr. Angus McSporran in Aberdeen. This clearly constitutes a counter example, which definitively falsifies the universal proposition originally put forward.... Allowing that this is indeed such a counter example, he ought to withdraw; retreating perhaps to a rather weaker claim about most or some. But even an imaginary Scot is, like the rest of us, human; and we none of us always do what we ought to do. So what in fact he says is: 'No true Scotsman would do such a thing!' (Flew 1975, p. 47).

Flew's example above of an argument with this structure is known as the No True Scotsman Fallacy (NTS). In the contemporary argumentation theory it is perceived as a dissociation strategy, which uses evaluative term to modify the meaning of a term according to one's needs - compare Halldén analysis of such PDs in literature, like 'true religion', 'true culture', 'true democracy' (1960). It is a term used for informal fallacies (where the inference is valid, but the argument is not sound). In its simplest form, it goes as follows:

CLAIM 1: Every $\mathrm{S}$ is $\mathrm{P}$.

PREMISE 1: There is at least one $\mathrm{S}$ that is not $\mathrm{P}$.

CLAIM 2: Every true $\mathrm{S}$ is $\mathrm{P}$.

Usually, the NTS scheme employs evaluative terms such as 'true', 'real', 'right', 'authentic', 'just', etc., to suggest that some desired object either be excluded from or be included in the extension of the definiendum. Meanwhile, the 'intention' that determines what should and what should not be included in the definition is what is known as the persuasive goal: in the above case, this is clearly a desire to rescue the proponent's first claim.

The NTS fallacy is thought to be deceptive in that the criterion for what it means to be a true Scot is known only to the proponent. Thus, one's claim can be changed ad hoc many times over, to avoid being falsified. In the context of the NTS scheme, it can often make a strong impression if someone appears to have grasped the 'real' essence of some term; in such circumstances, it acquires great manipulative force. However, if we consider such definitions from a nominalistic standpoint-i.e. instead of holding that definitions reach right down to the essence of being', we simply view them as argumentative devices-then it is no longer deceptive (Walton 2005, p. 181).

Let us consider a similar example: 


\section{Case 4}

- But if you want to be free, you've got to be a prisoner. It's the condition of freedom-true freedom.

- 'True freedom!' Anthony repeated in the parody of a clerical voice. 'I always love that kind of argument. The contrary of a thing isn't the contrary; oh, dear me, no! It's the thing itself, but as it truly is. Ask a diehard what conservatism is; he'll tell you it's true socialism. And the brewers' trade papers; they're full of articles about the beauty of True Temperance. Ordinary temperance is just gross refusal to drink; but true temperance, true temperance is something much more refined. True temperance is a bottle of claret with each meal and three double whiskies after dinner. Personally, I'm all for true temperance, because I hate temperance. But I like being free. So I won't have anything to do with true freedom'.

- 'Which doesn't prevent it from being true freedom', the other obstinately insisted.

- 'What's in a name?' Anthony went on. 'The answer is, practically everything, if the name's a good one. Freedom's a marvellous name. That's why you're so anxious to make use of it. You think that, if you call imprisonment true freedom, people will be attracted to the prison. And the worst of it is you're quite right. The name counts more with most people than the thing. They'll follow the man who repeats it most often and in the loudest voice. And of course "True Freedom" is actually a better name than freedom tout court. Truth-it's one of the magical words. Combine it with the magic of "freedom" and the effect's terrific' (Huxley 1955, pp. 122-123).

This is a counterargument to the NTS scheme: one might say that it is an argument removing an evaluative term from the definiendum. The proponent presents a new definition of 'freedom' (which is exactly contrary) by adding the evaluative term 'true'. The opponent reacts to it adequately by reducing it to absurdity and presenting a similar example of 'true temperance'. These arguments (NTS and counter-NTS) are considered to be semantic arguments, as they modify some meaning (whether it be a commonly accepted or a proposed one) in order to support a persuasive strategy.

One may argue that there are no semantic operations here: two separate terms are defined, these being 'freedom' and 'true freedom' (as a subgenus of freedom). However, the evaluative term 'true' has a 'normative' power that affects the previously invoked meaning and replaces it with something else. No one is interested in 'nontrue freedom' if there is such a thing as 'true freedom'. Similarly, no man wants to be an 'unreal man' if there is a possibility to be a 'real man', and no musician wants to play 'inauthentic music' if there is such a thing as 'authentic music'.

Still, one might want to claim that this kind of argumentation is trivial. After all, it is just about changing the popular meaning, but the legal definition is what it is and cannot be changed basing on one's personal judgement. Thus, such arguments - one might claim-are powerful only in popular use, not in law or science. In response, let us now analyse the following case: 
Case 5 Edward Schiappa, in his book Defining Reality: The Politics of Meaning, presents an analysis of the case of 'wetlands' and its role in George Bush's 1988 presidential election campaign (Schiappa 2003, pp. 69-88). It can be summarized as follows:

The term 'wetland' came to prominence in the environmental debates of the late 1960 's and early 1970's. It refers to an area saturated by water to the extent that only specially adapted plants can grow in it. Wetlands are very valuable to the ecology, according to scientists. Environmentalists, concerned about the disappearance of wetlands, especially due to building, have lobbied to protect these areas from development. Large amounts of money are at stake, and developers have engaged in many widely publicized legal actions and debates on the issue with environmentalists. Starting in the 1970's, efforts were made to introduce a standardized ecological definition of the term 'wetland'. A 1979 definition cited features such as the kind of soil, the kind of vegetation, and the way water is present. In 1989, a definition of this kind was codified in a federal government manual for identifying wetlands.

In the presidential election campaign of 1988, George Bush committed his administration to a policy of 'no net loss' of wetlands. By 1990, it became clear that if Bush kept to this commitment, he was in danger of alienating many of his pro-business, pro-development constituents. Accordingly, in August, 1991, a document produced by a Vice-Presidential task force proposed a redefinition of the term 'wetland', making the criteria stricter than those given in the 1989 manual. According to studies by scientists and environmentalists using the new definition, 50 million acres previously designated 'wetlands' would now be excluded. This so-called 'codification' of the definition in the 1989 manual was implemented in federal agencies without approval by the White House or Congress, and without inviting public comment, even though it met with intense opposition from environmentalists (Walton 2005, p. 165).

Evidently, certain political considerations prompted a move to alter the extension of the definition of 'wetlands' so that some (desired) objects would be excluded from it, in order that the latter would no longer be protected from potential development. This argumentation and its context can be presented as follows:

Context:

Primary Definition: Wetland is an area saturated by water to the extent that only specially adapted plants can grow in it.

Environmental Premise: Furnishing wetlands with buildings or estates should be forbidden by law.

Business Premise: It should be possible to build on wetlands.

The argument: 
Definition Premise: Wetland is an area that has 'saturated surface soil for 21 consecutive days in the growing season or standing water on it for 15 consecutive days of the year' (Schneider 1991).

No Net Loss Wetlands Policy Premise: No buildings or estates can be built on wetlands.

Individual Premise: Some given area $A$ has not had either saturated surface soil for 21 consecutive days in the growing season or standing water on it for 15 consecutive days of the year.

Conclusion: Building on area $A$ is not prohibited by the No Net Loss Wetlands Policy.

The contextual analysis here shows that Bush found himself confronted by a stalemate, inasmuch as the environmental premise and the business premise contradicted each other. Yet he needed to maintain both premises to gain the support of new environmentalist voters while at the same time holding on to that of the pro-business lobby. Therefore, he arrived at a genuine solution, which was to change the definition of 'wetland' so as to exclude some areas from it. These could then be developed, furnished with buildings, etc. At the same time he had kept his word, since he had not allowed anything to be built on wetlands.

One might say this was simply a case of introducing a regulative definition that brings new criteria into play for being a wetland-something not at all unusual in legislation. However, apprised of the relevant context one should be able to see that it is actually a persuasive definition-and that the argument presented above made was what we are here calling a semantic one. It is worth to note that the argument was not made by Bush himself-he rather made such arguments possible by the redefining move, so the business lobby may proceed with developing the areas which were no longer 'wetlands'.

The example shows that the type of semantic argument that uses a definition to change the extension of the definiendum is by no means trivial, and need not appeal to some negative connotations attached to the term in question. The argumentation presented here has a political and legal character, and its consequences are very serious. The structure of this type of argument may be summarized as follows: one has a persuasive goal (bringing and/or keeping both environmental and pro-business voters on board), and in order to realize it one shapes a definition to one's needs so that its extension excludes or includes some desired object(s). After such a redefinition, the inference one wanted to put forward can be made without any doubts arising, and the argument is therefore valid. This shows that PD is a very powerful tool in argumentation, and that constructing a model of such arguments will surely prove beneficial to logic, philosophy and law. 


\subsection{Arguments Including Quasi-Persuasive Definition}

\section{Case 6}

- Democracy is the policy of government that tries to bring morality and politics closer to one another until they coincide.

- Democracy is the form of government which gives, or tries to give, the people the illusion of their own sovereignty (Macagno and Walton 2014, p. 27).

These quasi-PDs might seem trivial — it is obvious that they are not meant the clear extension of a term 'democracy', but rather to include positive value connected with the term 'morality' (1) or to include negative value linked with the idea of 'living in the illusion of sovereignty' (2). One might build the argument accordingly to these values: "if you wish to live in a system that brings morality, then you should vote democrats" or "if you don't want to live in the illusion of sovereignty, you should not vote democrats". Such way of arguing seems to be naive, for the quasi-PD is easy to track and criticize. ${ }^{6}$ Thus, let us consider another example of quasi-PD of terrorism taken from Macagno and Walton book, which is a fragment of speech of Russian Foreign Minister from September 11, 2004 :

Case 7 Terrorists are bandits who hide behind political, religious or nationalist slogans to try to resolve questions that have nothing to do with what they publicly state (Macagno and Walton 2014, p. 28).

Such definition had a great persuasive power: Putin includes into the same category Al-Qaeda's attacks on World Trade Center (his speech took place in the third anniversary of the attack on Twin Tower) and actions of nationalists' movements of Chechens - and therefore the connotation of terrorists' attacks from September 2001 is extended to include Chechens' fighting for independence. Starting from this quasiPD one may build an argument from analogy: we condemn the actions of Al-Qaeda for they are terrorists, therefore we also should condemn the actions of Chechnya, for they are also terrorists. Putin's move is ingenious-he provides the same classification for the Chechens and Al-Qaeda and he also classifies the Chechens as 'terrorists' (which is against the common opinion on Chechens as freedom fighters). How does he do this? The argument, with the implicit premise, ${ }^{7}$ can be following:

Definition Premise: Terrorists are bandits who hide behind political, religious or nationalist slogans to try to resolve questions that have nothing to do with what they publicly state.

Individual Premise: Chechens, who are fighting for their independence, are hiding behind nationalist slogan to achieve their own political goals.

Conclusion: Chechens are terrorists.

\footnotetext{
${ }^{6}$ See the similar example of a detailed semantic analysis of definition of 'peacemaker' and 'warmonger' in Harold (2013).

${ }^{7}$ Although Putin himself did not state individual premise expressis verbis it may be reconstructed basing on his other speeches i.e. when he rejected to accept Chechnyan delegation comparing fighting Chechens to Osama bin Laden (Steele 2004).
} 
Having Chechens included into a definition of terrorists, now one may build further argument from definition to verbal classification e.g. basing on the given legal rule to delegalize all Chechen movements. However, one might also stop here, for the term 'terrorist' is very value-laden, and naming an individual or a group with it already influences on deteriorating one's image. In the given example the latter seems to be the case.

This shows how quasi-PD can be used to influence the meaning (by changing the connotation) to support the argument.

\subsection{Arguments Using a Synonymous Definition}

PDs of the third type in Pawłowski's typology are called 'synonymous definitions'. He himself referred to them as 'definitions aimed at exchanging a given term for another with a different emotional value'. However, during the course of further research into the topic this was changed to 'synonymous definitions' (Solecka 2010). This is not a 'definition' par excellence, as it does not furnish any criteria or detailed characterization, but rather consists of replacing a given term with another with a different connotation (this being positive, neutral or negative, depending on the persuasive goal). For example, if one wanted to advocate a pro-choice view on abortion, then one might replace 'abortion' with 'the free choice of a woman'. The expression 'free choice' has positive connotations, so it will change the neutral/negative emotional value of 'abortion'. On the other hand, if one wished to defend a pro-life view on the issue, one could replace 'abortion' with 'murder of fetus', so that the negative connotations of the latter influence the original term, thus facilitating acceptance of one's persuasive agenda. One might say that this is not a case of arguing, but rather a tactic of replacing one word with another (with a different emotional value). However, as will be shown, such a modification can lead to detailed arguments concerning the meanings of the terms used, (legal or lexical) definitions, the way such words are used in actual linguistic practice, etc.

Let us now consider another example, consisting in a correspondence-based discussion between Samuel A. Cosgrove and T.W. Jones that was published in the American Journal of Obstetrics and Gynecology in 1944.

Case 8 In their article 'A Consideration of Therapeutic Abortion', Samuel A. Cosgrove and Patricia A. Carter write the following:

[T]he fetus is a human individual with all the potentialities of every human being, and that its destruction is murder, only justifiable in the most extreme circumstances involving direct and imminent threat to the mother's life (Cosgrove and Carter 1944, p. 299).

Here, then, Cosgrove and Carter attempt to replace the term 'abortion' with the term 'murder of fetus', which not only has a very strong negative connotation, but also refers to something that-outside, at least, of certain potentially exceptional circumstances-is rightly regarded as a crime. Yet the real persuasive goal here is not that of changing the extension of the definiendum (and subsuming 'abortion' under the 
category of 'murder', i.e. 'crime'), but rather that of achieving acceptance of one's use of the expression 'murder of a fetus' interchangeably with 'abortion'.

In the very next issue of the American Journal of Obstetrics and Gynecology, T.W. Jones responds in these terms:

[I]n my belief, murder is an unpleasant and ugly word. His [Cosgrove's] definition of murder, premeditated destruction of human life, is excellent as far as it goes, but it does not go far enough. One word is needed for completion, namely, malice (Jones 1944, p. 895)

He then reaches for the dictionary definition of murder to support his own persuasive agenda:

I substantiate my viewpoint with definitions from Webster's International Dictionary: 'Murder-n-The offense of killing a human being with malice, pretense, or aforethought, express or implied; intentional and unlawful homicide' (Jones 1944, p. 895).

Thus, he concludes:

What frequently is spoken of as murder and justifiable murder is not murder at all, as no malice is involved, either according to law or the conscience of the individual. It is homicide (Jones 1944, p. 896).

What we see here is an attempt to show that it is inappropriate to use the term 'murder of the fetus' interchangeably with 'abortion', on account of its 'ugly and unpleasant' sound. This reveals the persuasive goal of Jones, which is to avoid terms with negative connotations when referring to abortion. To support this, he quotes a dictionary definition suggesting that every murder implies an element of malice (expressed or implied). Jones invokes this definition (although it is controversial, and could be rejected by the interlocutor ${ }^{8}$ ) as a premise, in order to be able to then conclude that abortion does not involve malice, and so is not murder.

\footnotetext{
8 We might well wonder what conveys authority to a dictionary definition? It is conceivable, of course, that the lexicographers have manipulated the meaning they assign to the term to support their own personal view on abortion. Referring to the dictionary shares in fact the structure of argument from authority. Except of the critical questions which one may formulate to such argument (Walton et al. 2008, pp. 309-10) critically ask: Does it really capture the way in which the word is actually used? Even so, is that really a pertinent consideration where this sort of discussion is concerned? Certain people may, after all, have deliberately sought to influence the way in which it is actually used. Shouldn't we therefore refer to legal definitions? But does that solve the problem? All these questions arise because of the presupposition that definitions capture the essence — the 'true' meaning — of the term (i.e. they implicitly adopt an essentialist approach). My own view is that if we wish to avoid this problem we should rather treat such definitions as arguments (i.e. adopt a nominalist approach), in order that the possibility of discussing whether this or that definition is one we are prepared to accept or not always remains open.
} 
In response, Cosgrove accepts the proposed definition of murder, but draws from it the opposite conclusion. His analysis goes further, seeking as it does to show that while it can be granted that murder does indeed involve malice, aborting a child itself presupposes an implied element of malice, too. To support this, he reaches for the definition of 'malice' from the same dictionary as Jones. Therefore, Cosgrove concludes, abortion fits the definition of murder after all:

Please note the last word of that quotation; the 'malice' need only be implied. This qualification is illuminated by part of the definition of malice according to the same dictionary on which you rely, as follows: 'Malice, n ... 4. Law ... legal malice ... does not necessarily consist in malice in fact, or actual malevolence toward the person injured ... it may consist in implied malice, that is ... wanton disregard of the rights of others'.

Therefore, murder may in some cases be adequately defined as the premeditated killing of a human being with wanton disregard of the rights of the victim. So defined, I consider my use of the word murder to designate the destruction of a fetus to be entirely justified (Cosgrove 1944, p. 896).

In the above example, we encounter an argument using synonymous persuasive definition (abortion= murder), a criticism of such a definition ('it is an ugly word', 'there is no malice in abortion, whereas malice is crucial for murder') and a further counter-response to this ('malice can also be implied, and is so in abortion, so it fits the definition of murder after all').

Let us now consider one more example of argumentation using a synonymous PD.

Case 9 On April 21st 2019, former US President Barack Obama tweeted the following:

@ BarackObama: The attacks on tourists and Easter worshippers in Sri Lanka are an attack on humanity. On a day devoted to love, redemption, and renewal, we pray for the victims and stand with the people of Sri Lanka. 21 April 2019, 4:02 PM. Tweet (Graham 2019).

Just a few hours later, thousands of people were discussing this, conveying their attitudes toward his use of the term 'Easter worshippers' instead of 'Christians'. Many conservatives expressed indignation, to the effect that "Easter worshippers is a euphemism used by people who don't want to say Christia", or "Christianity is not about worshipping Easter, but Jesus Christ", and so on (Graham 2019). Of course, we do not know the intention of Barack Obama himself in using the term 'Easter worshippers' instead of 'Christian'. Was he concerned that expressing solidarity with Christians might alienate his voters, who were mostly Democrats and/ or non-Christians with secular-progressive views? Was it about providing a positive synonym for a term that could carry negative connotations for Obama's followers, 
while at the same time expressing sympathy for Christians? These might well have been his persuasive goals. Using a synonymous PD to change the emotional attitude conveyed toward the object designated by the term certainly could prove to be a potent weapon in certain persuasive contexts - and, indeed, the reaction to Obama's tweet would seem to confirm this.

I have presented three types of semantic argument, using the three different types of PD given in Pawłowski's typology. However, there might also be arguments that modify or manipulate meanings for persuasive purposes, but without employing PDs (or any definitions) at all. We shall consider a potentially relevant example in the ensuing subsection.

\subsection{Arguments from Verbal Classification}

Case 10 In voluntary health insurance you generally get a poor return for your money because overhead and profits of the insurance company eat up huge chunks of the premiums you pay. On individual policies these companies spend for overhead and profits an average of about $60 \%$ of what you pay them and only about 40 cents of your premium dollar goes for benefits to policyholders. Obviously such insurance is a mighty poor buy (Walton 2008, p. 136).

It is worth emphasizing that the author here does not provide a definition of 'poor return'. Rather, he or she just makes a claim that something (a return) is poor-thus assigning some property to a particular object. Neither is it a partial definition that states a condition that is necessary but not a sufficient-just as when one says of something that it is beautiful, this does not constitute a partial definition of beauty. It is just assigning to an object the property of being beautiful. The argumentation scheme of such argument is following:

Individual Premise: In voluntary health insurance only about 40 cents of premium dollar goes for benefits to policyholders.

Classificatory Premise: $40 \%$ return in health insurance can be described as a poor return.

Conclusion: Voluntary health insurance is a poor return for money.

In the above case, the key term used is 'poor'. Whether something like a return on one's money counts as poor or not tends to depend on one's economic circumstances at the time in question. Nevertheless, the argument seems to lend strong support to the claim that it would not be a good idea to purchase voluntary health insurance, as the return is poor. Here is the scheme for such an argument (Walton et al. 2008, p. 319):

Individual Premise: A possesses some property $F$.

Classificatory Premise: For all $x$, if $x$ possesses property $F$, then $x$ can be classified as possessing property $G$.

Conclusion: A possesses property $G$. 
A simple argument along such lines might be the following: 'Garfield has sharp fangs, and whatever has sharp fangs is dangerous, therefore Garfield is dangerous'. However, an argument from verbal classification will usually have a far more complex structure: it will contain some justification for entertaining the individual premise (Does Garfield indeed have sharp fangs?), as well as some reasons for adopting the classificatory premise (Is every animal with sharp fangs truly dangerous?).

This tactic was partly described by Bentham in The Book of Fallacies: he makes a distinction there between 'eulogistic' and 'dyslogistic' terms - the former might be: industry, honour, piety, generosity, gratitude, and the latter might be: lust, avarice, luxury, covetousness, prodigality $(1824$, p. 214). Classifying something with such emotionally charged terms may not only change one's attitude towards the object, but also impact on one's behaviour.

In Argumentation Schemes, we come across two types of counter-argument with respect to verbal classification (Walton et al. 2008, pp. 319-320): argument from vagueness of a verbal classification (where the discussion requires a certain degree of precision, while the classification offered is too vague), and argument from arbitrariness of a verbal classification (where the discussion calls for a certain level of nonarbitrary classification, but the key property is assigned in an arbitrary way). These two might be classified as possible replies to instances of argument from verbal classification; therefore, they count as semantic in that they seek to criticize an attempt to modify meanings deployed in a given discussion.

One might think that argument from verbal classification is trivial. However, as Walton, Reed and Macagno note, the classificatory premise is very often an implicitly held one, backed by common or shared knowledge:

A famous example is that of a religious discussion where the interlocutor's position is labelled as 'heresy'. Based merely on this verbal classification, it is concluded that the position itself is wrong, on the implicit basis of the generalization that every heresy is wrong. The concealed assumption is the loaded nature of the term 'heresy', a matter of definition (Walton et al. 2008, p. 67).

Here, another problem arises, which is that as in the above example, we can see that discussing a verbal classification often implies explicating a definition. If the general classification is obvious between disputants, as in 'all terrorists are dangerous fanatics who need to be locked up' (Walton et al. 2008, p. 67), then the definition will not need to be analysed, as it issues from shared knowledge. However, if that is not so-imagine, say, some sophisticated legal debate where definitions are required to be precise (argument from vagueness of a verbal classification) - then often discussion will turn into a search for the best definition capable of supporting or undermining the classificatory premise. We shall consider an example of the latter next.

\subsection{Arguments from Definition to Verbal Classification}

Case 11 A legal rule forbids you to take a vehicle into the public park. Plainly this forbids an automobile, but what about bicycles, roller skates, toy automobiles? What 
about airplanes? Are these, as we say, to be called 'vehicles' for the purpose of the rule or not? (Hart 1958, p. 607).

Let us imagine a little boy with his tricycle and a policeman, who stops him. Should the policeman give a ticket to the little boy? Did he break the law? This depends on the definition of 'vehicle'. Many countries and organizations (like the United Nations) define a vehicle by its function: i.e. it is something used for the carriage of persons or goods (UNESC 2017, p. 5). Can we apply such a definition here?

Definition Premise: If $x$ is used to carry persons or goods, then $x$ is a vehicle (If $x$ has the property of carrying persons or goods, then $x$ is a vehicle).

Individual Premise: The tricycle is used to carry persons. (The tricycle has the property of carrying persons).

Conclusion: The tricycle is a vehicle.

Well, as soon as one has adopted such a definition of 'vehicle' and shown that the tricycle fits this same definition (based on its possession of a certain property-i.e. carrying persons), one can proceed with the relevant instance of argument from definition to verbal classification:

Definition Premise: The tricycle fits the definition of 'vehicle'.

Classificatory Premise: For all $x$, if $x$ fits the definition of 'vehicle', then $x$ must not be taken into a public park.

Conclusion: The tricycle must not be taken into a public park.

The argumentation is valid, and seems sound. But let us consider another example. What about a wheelchair? It has wheels, like most vehicles, and is used to carry persons. So does that mean that disabled people are not to be permitted to enter public parks on their wheelchairs? Of course, we would say, that is not the intent of the law. Such an interpretation is recognized as problematically literal, in that one is obeying the letter of the law but not necessarily its spirit. So if the definition does not provide a clear answer here, what could do so?

Here we face something that is a matter of legal interpretation: can we subsume wheelchairs or tricycles under the category of vehicles? If we agree to this, then the subsequent syllogisms will ensue automatically. This is the argumentation scheme that Walton, Reed and Macagno call argument from definition to verbal classification (Walton et al. 2008, p. 319):

Definition Premise: $A$ fits definition $D$.

Classificatory Premise: For all $x$, if $x$ fits definition $D$, then $x$ is classified as having the property $G$.

Conclusion: $A$ has the property $G$.

The most problematic element within the scheme is, of course, the definition. Is the latter really adequate? Is there an alternative possible definition? Is the verbal 
classification within the classificatory premise based on some merely stipulative, arbitrary or biased definition, which we could cast doubt on?

This case points to the problem of the presence of pre-established assumptions in the law and legal definitions. We shall not inquire into this philosophical issue here, as it would require a separate investigation; it is enough just to see how one might modify the interpretation of some term's meaning even in legal definitions to lend support to one's persuasive goals. Such an argument, which modifies a definition, or invokes a definition 'tailor-made' for classifying something in a certain way, also represents a type of semantic argumentation.

Arguing from verbal classification often leads to analysis of definitions, but need not always do so. What is more, these definitions need not be-though they sometimes are-persuasive, which makes the analysis of such arguments a more complex affair. Therefore, I have distinguished between semantic arguments using persuasive definitions and semantic arguments from definition to verbal classification.

In the above section, I have presented five different types of semantic argument: three based on different types of persuasive definition, two on verbal classification. Now I shall try to construct a typology of such arguments, in order to arrive at a clear overview of the different ways in which modifications of meaning can influence argumentation.

\section{A Typology of Semantic Arguments}

Semantic arguments, as I have presented them so far, can be divided up taxonomically in terms of how they modify the meanings present in a given discussion: by using persuasive definition or verbal classification. This implies that there is no way to modify meanings in argumentation other than through PDs or verbal classification. There is also the possibility-mentioned above-that an instance of argument from verbal classification will itself be backed by a definition that is persuasive. This is a more complex scenario, but also needs to be taken into consideration, given that it is possible.

Let us begin with the first division. Semantic arguments can be divided into two kinds: those that use definitions to modify meanings, and those that do not use definitions-at least explicitly - to modify them. This yields two basic types of semantic argument: arguments using (persuasive ${ }^{9}$ ) definitions and arguments using classification. ${ }^{10}$ As mentioned before, there is another way to modify the meaning of a term apart from redefinition: namely, verbal classification. When one does not implicitly or explicitly redefine a term, but simply classifies something as such or assigns a

\footnotetext{
${ }^{9}$ Every definition employed in semantic arguments (i.e. every definition used to modify a meaning) is necessarily persuasive, given the above characterization of PD.

10 Similar trait can be found in Arthur Hastings' unpublished $\mathrm{PhD}$ dissertation, where he distinguished 9 types of arguments - and two of them were based on the meaning: Argument from Criteria to a Verbal Classification and Argument from Definition to Characteristics. The purpose of the former is "to classify or categorize a situation; to prove that a certain label, classification, or verbal description may properly be attached to an aspect of reality" (Hastings 1962, p. 36). The latter reminds the locus "from definition to the defined terms"(Rigotti and Greco 2019, p. 189), for it starts with a given definition of the par-
} 


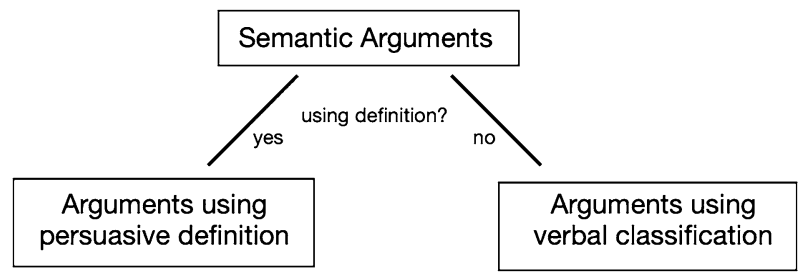

Fig. 1 First-level division of semantic arguments

certain property to something, then-according to the terminology of Argumentation Schemes - this is to be referred to as verbal classification. Thus the division is complete and disjoint: there is no way to modify the meaning (i.e. denotation or connotation) of a term other than through redefinition or verbal classification, and these two differ in a clear way: one uses definition, the other does not. This division is represented in Fig. 1.

This division assumes division made by Perelman on arguments to definition (which are arguments using persuasive definition) and arguments from definition (arguments from definition to verbal classification). Arguments using PD are always to definition, and classification argument which employ definition are always from definition. Above division is broader than the Perelman's, for it also includes arguments from verbal classification (which also modify meaning, but without definition). It is also worth to note that implicit definition does not blur this distinctionwhen definition modifies the meaning implicitly, then it is persuasive. If it does not include definition at all, but simply assigns some property to given object, then it is a verbal classification.

Now, arguments containing a PD can be divided up according to developed Pawłowski's typology of PDs presented earlier. Meanwhile, instances of argument from verbal classification can be divided up accordingly to Walton, Reed and Macagno's characterizations: it may be that one simply assigns some property $F$ to something, or that one provides a definition in support of such a verbal classification (Walton et al. 2008, p. 67). On the other hand, where argument from definition to verbal classification is concerned, such cases might need further elaboration: if the definition that supports the verbal classification is persuasive, then it should be analysed as a case of Argument using Persuasive Definition (of a sort appropriate to the type of PD employed)—something we shall examine later. In response to an instance of argument from verbal classification, one might possibly formulate counterarguments from arbitrariness and/or counterarguments from vagueness, as already discussed. These divisions are set out in Fig. 2 below.

Footnote 10 (continued)

ticular object. After having the definition accepted, all "the implications or applications of the definition must be accepted also" (Hastings 1962, p. 46). Both types of arguments share the same trait-both are based on the given meaning (in the definition or classification), and therefore they both are 'semantic'. For this reason Rigotti and Greco analyse this argument together "because they both pertain to a broad area that has traditionally been named definition or description" (2019, p. 188). 


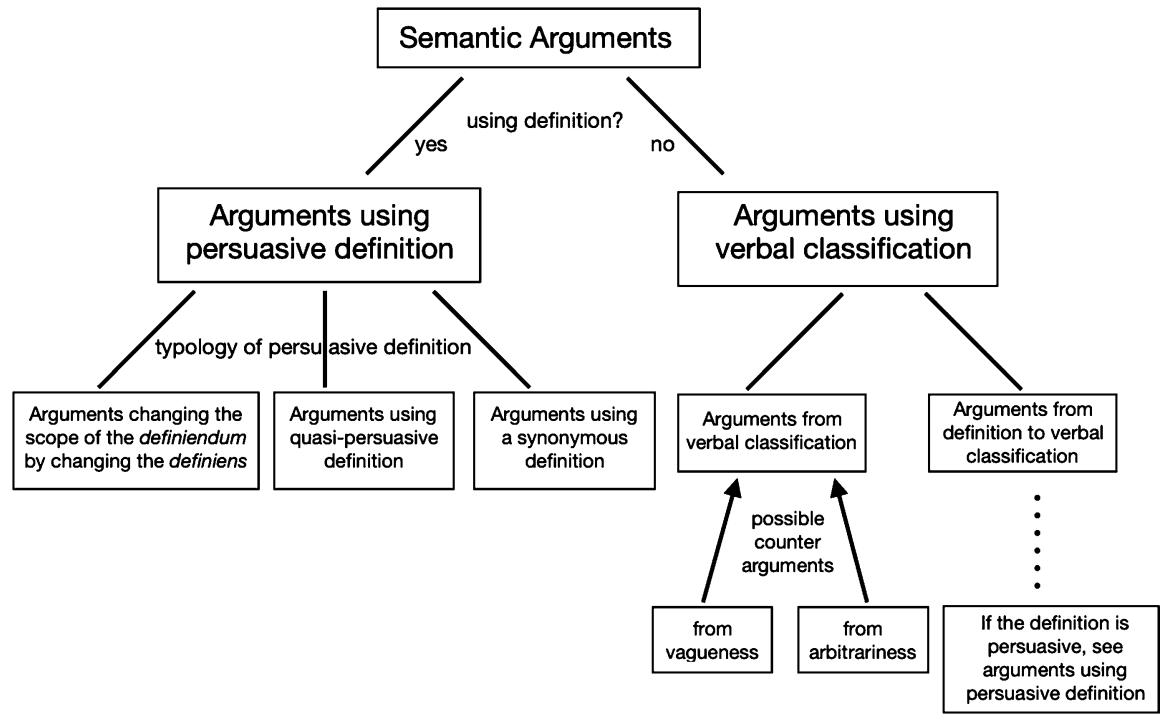

Fig. 2 Second-level division of semantic arguments

When analysing arguments using PDs, we may pose a question that is potentially helpful when it comes to making further divisions: does a PD dissociate elements of a single meaning, so that these now count as multiple distinct meanings, or does it synthesize several such meanings into just one? Depending on the answer we give, we may call such arguments dissociative or synthetic. Having this said, we ought now to examine the typology for cases of Argument using Persuasive Definition.

In the first such type, which arguments change the extension of the definiendum by changing the definiens, can be divided into further subtypes along the following lines: there are PDs that dissociate a single meaning into multiple meanings, and there are arguments which synthesize two (or more) different meanings into one (See Perelman and Olbrechts-Tyteca's concept of dissociation: Perelman and Olbrechts-Tyteca 1969, pp. 411-50). In Case 2, the lawyer who is defending his client accused of attempted bribery subjects the meaning of 'bribe' to a form of dissociative division by means of the concept of 'significant value', creating in this way another meaning for the term 'bribe': there are now bribes with significant value (that should be prohibited by law), and ones without such value (that should not be considered socially harmful)_not a 'real' bribes. Thus, the lawyer dissociates a concept of bribe into two kinds of bribes, and then implicitly assumes that only the one of them is a bribe. This is an example of a dissociative semantic argument using a PD to change the definiens. On the other hand, to illustrate a synthesizing argument of this kind, let us now turn to our next example.

Case 12 You are a notorious liar, and I am going to prove it! You promised several times that you would donate to our society, but you never did! If one does not keep promises, then one speaks untruth! And 'speaking untruth' means simply 'lying'. Therefore you are a liar! (see Hołówka 2012, pp. 116-117). 
Here we can see a two-fold semantic modification occurring. Firstly, the meaning of 'not keeping promises' is altered by expanding its extension to include 'speaking untruth'. Secondly, the meaning of 'speaking untruth' is also expanded, to include 'lying'. This modification is obviously unjustified, as breaking a promise is something different from speaking untruth, and speaking (i.e. uttering) untruth-according to the theory of lying - is not in fact itself the same as lying (since the latter must involve an intention to deceive). Thus, three different terms are synthesized into one in order to achieve the persuasive goal of calling the interlocutor a liar on account of their not having kept their promises. This is an example of a synthesizing semantic argument using a PD to change the definiens. Such arguments might be divided into dissociative (dissociating a single meaning into two or more senses) and synthesizing (broadening an extension so it includes two or more other terms).

Within this type we one can also distinguish the arguments adding an evaluative term to the definiendum so that a modification of meaning occurs, and this is achieved by introducing evaluative and vague operators in order to influence our perception of some established meaning. This invariably involves dividing the meaning of some term into 'true-Xs' and 'not-true-Xs': for example, the unitary term 'man' is, in effect, split into two classes ('real men' and 'not-real men') by means of the addition of the adjective 'real'. Thus, arguments using persuasive definition that add an evaluative term to the definiendum are necessarily dissociative, in that they always split one term into two (or more) terms. The structure of division does not go further where this type of argument is concerned.

Meanwhile the second such type, consists of arguments based on quasi-persuasive definitions, which do not change the denotation of the definiendum, but simply reformulate the definiens so its connotation changes according to persuasive goal. As it was shown it is also a powerful of arguing, even though it does not change the extension of the definition, it influences its connotation, and therefore can introduce a new semantic family, which can be used in further argumentation (e.g. by building analogy). As this type of argument is based on the modification of connotation, the category of dissociating/synthetizing does not apply here.

The third and final such type is the kind of argument that uses a synonymous definition, where the latter in effect proposes a synonym for a given term, and this is one whose emotional value (connotation) is intended to lend support to one's persuasive goal. Thus, one term is replaced with another, on the basis of a tacit assumption that they are synonymous (but where the latter term is viewed as preferable, given its distinctive connotations). Hence, such arguments will necessarily be of the synthesizing kind, in that they always involve combining two terms into one, often while emphasising that one term 'is better suited' than the other. The taxonomic division just outlined can be presented as in Fig. 3 below:

The third-level division introduced at this stage is the last in the typology of semantic arguments. Consequently, they can be divided into those which use PDs and those which use verbal classification. Arguments with PDs can be subdivided in line with developed Pawłowski's typology of PDs - and then again on the basis of their dissociative or synthesizing character. Arguments using verbal classification, meanwhile, can be divided into those which are based directly on verbal classification and those which support verbal classification with a definition. 


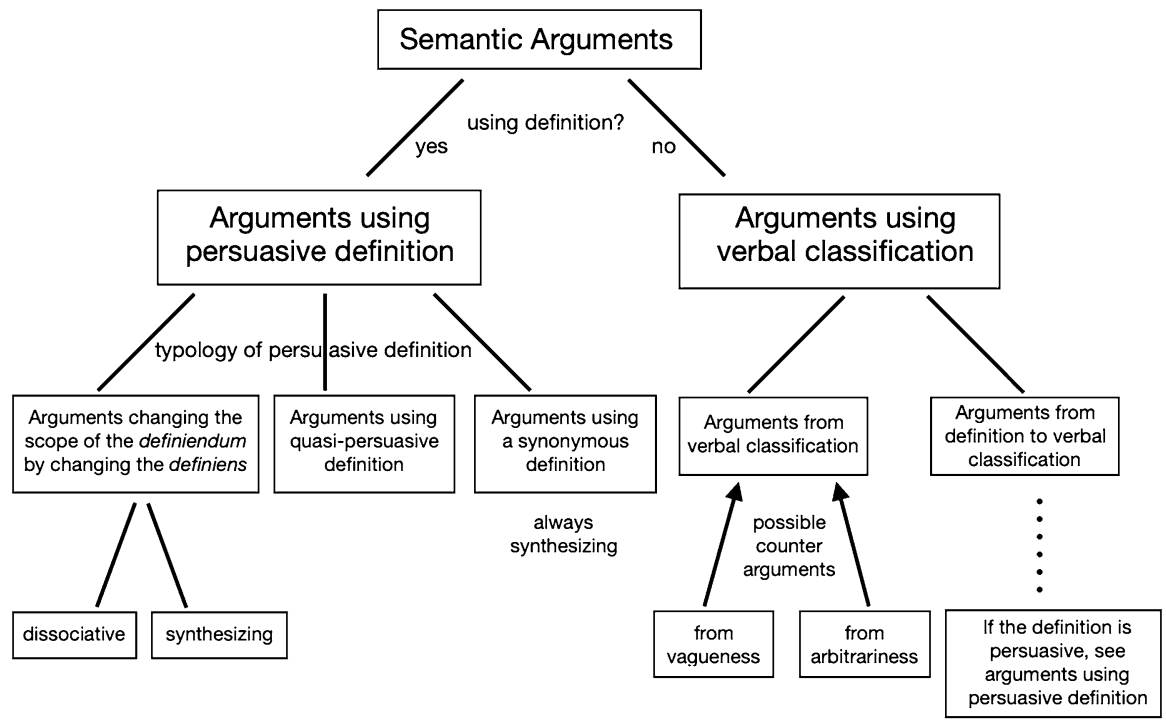

Fig. 3 Third-level division of semantic arguments

Diagram 1: Argument using persuasive definition

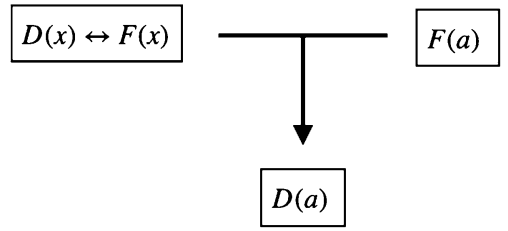

It is also worth to note that the argumentation schemes for the above types differs only with the three basic types: argument using persuasive definition, argument from verbal classification and argument from definition to verbal classification. Argument using the persuasive definition, despite of various types of definition involved, share the same basic structure: definition premise, individual premise and conclusion, as it was presented in the examples analysed before. Below I present the argument diagram with in formal language-the definition premise includes a definition stating that if and only if $x$ has a property $F$ then $x$ fits definition $D$. The individual premise states that $a$ has property $F$. Then conclusion is that $a$ fits definition $D$.

Argumentation schemes for arguments using verbal classification are the same as in Walton, Reed and Macagno:

Argument from persuasive definition to verbal classification, which was mentioned before, and which is the very common combination of two arguments (argument using PD and argument from definition to verbal classification) has a following structure:

The present attempt to construct a typology of semantic arguments captures, I hope, the many ways in which modifications of meaning can be employed in 


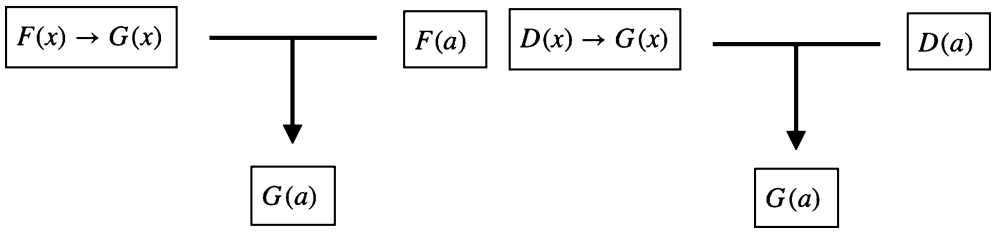

Diagram 2 \& 3: Argument from verbal classification and argument from definition to verbal classification

Diagram 4: Argument from persuasive definition to verbal classification

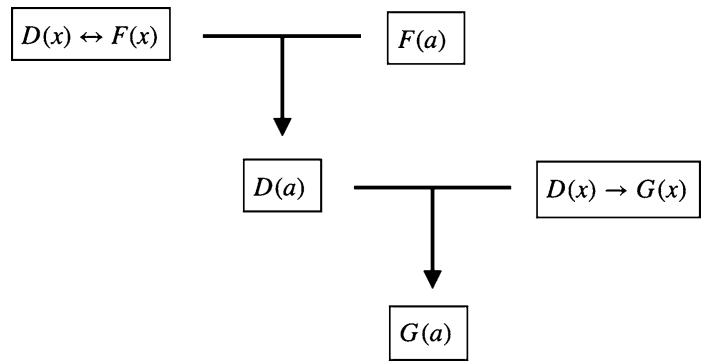

argumentation. The analysis of examples was supplemented with argumentation schemes and argument diagram with formal structure of each type.

\section{Conclusion}

What, then, is a semantic argument? Put simply, it is an argument that modifies the meaning of a term being used, so that one may achieve one's persuasive goal. It is perhaps best illustrated by comparing it to other types of argumentative strategy. For example, there are various ways in which one could seek to argue, say, that democracy in France is somehow being violated. One could build an analogy between the political situation in France and in Saudi Arabia, which is similar in certain respects to France-so that if one is not prepared to call Saudi Arabia democratic, one should not call France democratic either. Such an argument is said to proceed 'from analogy'. Another way would be to appeal to some experts, such as political scientists, who claim that democracy in France is being violated, as a basis for declaring that this is indeed the case. This is known as an argument 'from authority'. Yet another would be to redefine 'democracy' so that it is longer applicable to France-e.g., by claiming that 'democracy is violated when, as is indeed the case in France, there is a president in the government, because true democracy only exists when the people govern through their representatives, and not when a dictator such as a president does so'. Such an argument is 'semantic'.

Briefly summing up, my aim here has been to present the notion of a semantic argument, which so far remains not very widely known in argumentation theory. Its name comes from the Polish logician, Teresa Hołówka, who was the first to identify a new kind of argumentation based on semantic modification. I have sought to elaborate various aspects of the concept by appealing to Stevenson's and Pawłowski's 
findings relating to both persuasive definitions, Perelman's findings on dissociation and contemporary work on verbal classification. On the basis of these, I have been able to construct a typology of semantic arguments of the sort needed if one is to achieve an effective model of semantic argumentation, with its types and its criteria of validity or applicability in respect of various discourses.

Open Access This article is licensed under a Creative Commons Attribution 4.0 International License, which permits use, sharing, adaptation, distribution and reproduction in any medium or format, as long as you give appropriate credit to the original author(s) and the source, provide a link to the Creative Commons licence, and indicate if changes were made. The images or other third party material in this article are included in the article's Creative Commons licence, unless indicated otherwise in a credit line to the material. If material is not included in the article's Creative Commons licence and your intended use is not permitted by statutory regulation or exceeds the permitted use, you will need to obtain permission directly from the copyright holder. To view a copy of this licence, visit http://creativecommons.org/licen ses/by/4.0/.

\section{References}

Aberdein, Andrew. 2000. Persuasive definition. In Argumentation at the Century's Turn, edited by Christopher W. Tindale, Hans V. Hansen and Elmar Sveda. Windsor: OSSA (Ontario Society for the Study of Argumentation) Proceedings.

Bentham, Jeremy. 1824. The book offallacies. London: John and H. L. Hunt.

Cosgrove, Samuel A. 1944. Reply by Dr. Cosgrove. American Journal of Obstetrics and Gynecology 48 (6): 896.

Cosgrove, Samuel A., and Patricia A. Carter. 1944. A consideration of therapeutic abortion. American Journal of Obstetrics and Gynecology 48 (3): 299-314.

Eemeren van, Frans H. 2010. Strategic maneuvering in argumentative discourse: extending the pragmadialectical theory of argumentation. Amsterdam: John Benjamins Publishing Company.

Feng, Jieyun, Fan Zhao, and Aiqing Feng. 2020. Strategic manoeuvring by dissociation in corporate crisis communication: The case of the 2017 United Airlines' passenger dragging-off incident. Argumentation. https://doi.org/10.1007/s10503-020-09530-2.

Flew, Antony. 1975. Thinking about thinking: Or, Do I sincerely want to be right? London: Collins Fontana.

Graham, Ruth. 2019. Why conservatives are so angry about Obama's reference to "Easter Worshippers". https://slate.com/human-interest/2019/04/easter-worshippers-obama-hillary-conservative-backlash. html.

Halldén, Sören. 1960. True love, true humour and true religion: a semantic study. Lund: Gleerlup.

Harold, James A. 2013. Distinguishing the lover of peace from the pacifist, the appeaser, and the warmonger. Forum Philosophicum 18 (1): 5-17.

Hart, H.L.A. 1958. Positivism and the separation of law and moral. Harvard Law Review 71 (4): 607.

Hastings, Arthur. 1962. A reformulation of the modes of reasoning in argumentation. Ph.D., Northwestern University.

Hołówka, Teresa. 2012. Kultura logiczna w przykładach. Warszawa: Wydawnictwo Naukowe PWN.

Huxley, Aldous. 1955. Eyeless in Gaza. London: Chatto \& Windus.

Jones, T.W. 1944. Is abortion murder? American Journal of Obstetrics and Gynecology 48 (6): 895-896.

Macagno, Fabrizio, and Douglas Walton. 2008. The argumentative structure of persuasive definitions. Ethic Theory Moral Practice 11: 525-549. https://doi.org/10.1007/s10677-008-9119-5.

Macagno, Fabrizio, and Douglas Walton. 2008. Persuasive definitions: values, meanings and implicit disagreements. Informal Logic 28 (3): 203-228.

Macagno, Fabrizio, and Douglas Walton. 2014. Emotive language in argumentation. New York: Cambridge University Press.

Parry, William T., and Edward A. Hacker. 1991. Aristotelian logic. New York: SUNY Press. 
Pawłowski, Tadeusz. 1978. Tworzenie pojęć $i$ definiowanie $w$ naukach humanistycznych. Warszawa: Państwowe Wydawnictwo Naukowe.

Perelman, Chaïm, and Lucie Olbrechts-Tyteca. 1969. The new rhetoric: a treatise on argumentation. Translated by John Wilkinson and Purcell Weaver. Notre Dame: University of Notre Dame Press.

Pruś, Jakub. 2019. Argumentacja semantyczna - podstawowe pojęcia i problemy definicyjne. Res Rhetorica 6(4). https://doi.org/10.29107/rr2019.4.3.

Rigotti, Eddo, and Sara Greco. 2019. Inference in argumentation: a topics-based approach to argument schemes. Cham: Springer.

Schiappa, Edward. 2003. Defining reality: definitions and the politics of meaning. In Rhetorical philosophy and theory, edited by David Blakesley. Carbondale and Edwardsville: Southern Illinois University Press.

Schneider, Keith. 1991. Bush announces proposal for wetlands. https://www.nytimes.com/1991/08/10/us/ bush-announces-proposal-for-wetlands.html. Accessed 12 Sept 2019.

Solecka, Grażyna. 2010. Dyskursywny charakter definicji. In Argumentacja $i$ racjonalna zmiana przekonań, edited by I. Trzcieniecka-Schneider W. Suchoń, D. Kowalski, 45-51. Krakow: Wydawnictwo Uniwersytetu Jagiellońskiego.

Steele, Jonathan. 2004. Angry Putin rejects public Beslan inquiry. Guardian. https://www.theguardia n.com/world/2004/sep/07/russia.chechnya?INTCMP=ILCNETTXT3487.

Stevenson, Charles L. 1938. Persuasive definitions. Mind 47: 331-350.

Stevenson, Charles L. 1944. Ethics and language. New Haven: Yale University Press.

UNESC. 2017. Consolidated resolution on the construction of vehicles (R.E.3). In ECE/TRANS/ WP.29/78/Rev.6, edited by United Nations Economic and Social Council.

Walton, Douglas. 2001. Persuasive definitions and public policy arguments. Argumentation and Advocacy 37: 117-132.

Walton, Douglas. 2005. Deceptive arguments containing persuasive language and persuasive definitions. Argumentation 19: 159-186. https://doi.org/10.1007/s10503-005-2312-y.

Walton, Douglas. 2008. The case of redefining "planet" to exclude Pluto. Informal Logic 28 (2): 129-154.

Walton, Douglas, and Erik C.W.. Krabbe. 1995. Commitment in dialogue: basic concepts of interpersonal reasoning. Albany: State University of New York Press.

Walton, Douglas, Christopher Reed, and Fabrizio Macagno. 2008. Argumentation schemes. New York: Cambridge University Press.

Zarefsky, David. 2006. Strategic maneuvering through persuasive definitions: implications for dialectic and rhetoric. Argumentation 20 (4): 399-416.

Publisher's Note Springer Nature remains neutral with regard to jurisdictional claims in published maps and institutional affiliations. 